\title{
Hormone concentrations in the caudal vena cava during the first ovarian follicular wave of the oestrous cycle in heifers
}

\author{
F. M. Rhodes ${ }^{1}$, L. A. Fitzpatrick ${ }^{1}$, K. W. Entwistle ${ }^{1 *}$ and J. E. Kinder ${ }^{2}$ \\ ${ }^{1}$ Department of Biomedical and Tropical Veterinary Sciences, James Cook University of North \\ Queensland, Townsville, Q4811, Australia; and 'Department of Animal Science, University of Nebraska, \\ Lincoln, NE 68583-0908, USA
}

\begin{abstract}
Changes in pulsatile secretion of LH, FSH, oestradiol and progesterone were related to the growth phase, early plateau phase and regression phase of the first ovarian dominant follicle of the oestrous cycle in Bos indicus heifers. Relationships between these hormones during the three phases were also investigated. Accurate measurements of episodic ovarian steroid secretion were obtained by catheterizing the caudal vena cava via the lateral saphenous vein; the tip of the catheter was positioned just cranial to the ovarian vein using transrectal ultrasonography. Pulsatile secretion of oestradiol was increased only during the growth phase of the dominant follicle and was associated with high frequency release of LH pulses. However, mean concentrations of oestradiol were reduced when the dominant follicle attained its maximum diameter. Between the growth and plateau phases, as the amount of progesterone released increased and oestradiol released decreased, LH pulse frequency and mean concentration of $\mathrm{LH}$ decreased. Pulses of $\mathrm{LH}$ released were followed within $15 \mathrm{~min}$ by increases in mean concentrations of oestradiol $(P<0.001)$; however, there was no apparent relationship between $\mathrm{LH}$ and progesterone release $(P=0.19)$. Although there was little evidence of pulsatile release of $\mathrm{FSH}$, mean concentrations of FSH were increased by $0.2 \mathrm{ng}$ $\mathrm{ml}^{-1}(P=0.04)$ during the plateau phase, which was on average 2.1 days before the day of emergence of the second dominant follicle of the oestrous cycle. This increase in FSH, in conjunction with the decrease in secretion of oestradiol, may be an indication of the loss of functional dominance by the first dominant follicle of the oestrous cycle.
\end{abstract}

\section{Introduction}

Development of the largest follicle in the bovine ovary has been divided into phases of selection, dominance and atresia (Ireland and Roche, 1987). During the selection phase, several follicles begin to grow, but only one follicle continues to increase in size, becoming larger than all other follicles. This follicle is termed the dominant follicle and is responsible for the increased concentrations of oestradiol in the blood observed during pro-oestrus and early dioestrus (Ireland et al., 1984; Guilbault et al., 1993a). During the luteal phase of the oestrous cycle, the dominant follicle ceases growth and undergoes atresia, being replaced by a second or third dominant follicle (Savio et al., 1988). This sequence of events is mainly under gonadotrophin control (Driancourt, 1991), although a number of intraovarian peptides may also be involved (Findlay, 1993).

Changes in secretion of gonadotrophins during different phases of the bovine oestrous cycle have been examined in a number of studies in which serial blood samples were obtained for periods of 12-24 h. Rahe et al. (1980) found that the

\footnotetext{
*Present address: Faculty of the Sciences, The University of New England Armidale, NSW 2351, Australia.

Received 30 September 1994.
}

frequency of LH pulses decreased and the amplitude of pulses increased during the mid-luteal phase (day 10 or 11) compared with the early luteal phase (day 3 ) of the oestrous cycle, although there were no differences in mean concentrations of LH. Similarly, Walters et al. (1984) found that the frequency of LH pulses was lower during the mid-luteal compared with the early luteal phase of the oestrous cycle, although differences in LH pulse amplitude among different parts of the luteal phase were not detected. The characteristics of the release of gonadotrophin pulses and their relationship to ovarian steroid release have not been examined in relation to the morphological changes of the first dominant follicle that develops during the bovine oestrous cycle.

Venous blood samples have to be collected at a site close to the ovary to obtain accurate measurements of episodic ovarian steroid release. Several methods have been described for the direct sampling of ovarian effluent, including autotransplantation of the ovary and uterus to the neck in ewes (Baird et al., 1976), surgical catheterization of the utero-ovarian vein (Ireland et al., 1984) and cannulation of the medial coccygeal vein (Walters et al., 1984) in cattle. Benoit and Dailey (1991) described a simple technique for catheterization of the caudal vena cava via the lateral saphenous vein. A modification of this technique was used in the current experiment, incorporating 
insertion of the catheter under local anaesthesia and positioning of the catheter tip within the caudal vena cava using transrectal ultrasonography.

The aim of this experiment was to evaluate patterns of release of $\mathrm{LH}, \mathrm{FSH}$, oestradiol and progesterone in ovarian venous samples during the growth, early plateau and regression phases of the first dominant follicle of the oestrous cycle in Brahman (Bos indicus) heifers. Relationships between the patterns of release of these hormones during the different phases of ovarian follicular development were also investigated.

\section{Materials and Methods}

\section{Experimental animals}

Six Brahman heifers, 2 years of age, weighing on average ( \pm SEM) $317.9 \pm 3.1 \mathrm{~kg}$ and having oestrous cycles of mean duration $21.1 \pm 0.68$ days were used during the months of October and November. All animals were accustomed to daily ultrasound examinations and had previously been tethered indoors. During the course of serial blood sampling periods, heifers were fed $1-2 \mathrm{~kg}$ cottonseed meal with access to hay and water ad libitum. Between sampling periods, heifers were kept in a small native pasture paddock with access to hay ad libitum and an $8 \%$ urea-molasses supplement.

\section{Experimental protocol}

The ovaries of all heifers were examined daily, between 07:00 $\mathrm{h}$ and 08:00 $\mathrm{h}$, for two complete interovulatory intervals, using transrectal ultrasonography $(7.5 \mathrm{MHz}$ transducer, Aloka $210 \mathrm{DX})$ commencing on the day of ovulation. Ovulation was determined by the disappearance of a dominant follicle from the ovary and the subsequent formation of a corpus luteum in the same position on the ovary. The size and position of corpora lutea and all follicles $\geq 5 \mathrm{~mm}$ in diameter were recorded as described by Savio et al. (1988). Day of emergence was defined as the day on which a follicle $\geq 5 \mathrm{~mm}$ was first detected.

Three periods of serial blood collection were defined with reference to the growth of the first dominant follicle of the second interovulatory interval: (i) growth phase, when a follicle $\geq 7 \mathrm{~mm}$ was first detected ( $2.5 \pm 0.2$ days after ovulation), (ii) plateau phase, the second consecutive day when there had been no increase in the size of the dominant follicle or when the diameter of the first dominant follicle was $\geq 10 \mathrm{~mm}(5.6 \pm 0.3$ days after ovulation), since the maximum diameter of dominant follicles in Bos indicus heifers is, on average, $10 \mathrm{~mm}$ (Rhodes et al., 1994); and (iii) regression phase, when the dominant follicle started to decrease in size or the second wave of follicles had emerged ( $8.2 \pm 0.4$ days after ovulation).

\section{Catheterization}

Before the first day of blood collection from the caudal vena cava, heifers were individually restrained and sedated with an i.m. injection of $0.1-0.2 \mathrm{mI}$ acepromazine maleate (10 mg $\mathrm{ml}^{-1}$ ). The caudal vena cava was catheterized via the lateral

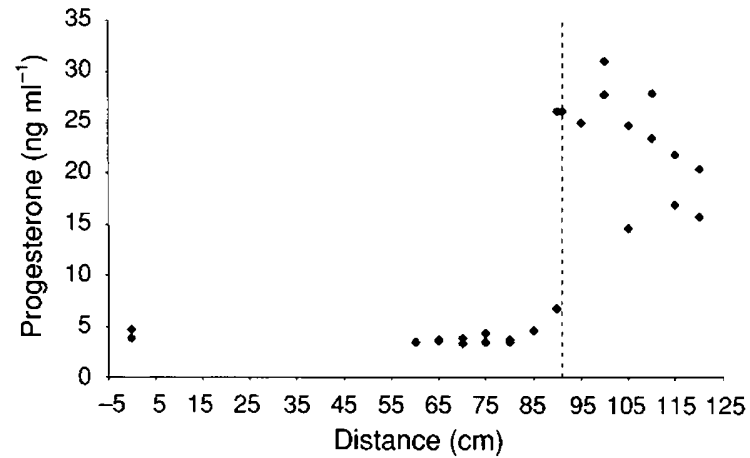

Fig. 1. Concentrations of progesterone in plasma samples obtained from the caudal vena cava at different sites of catheter insertion in one heifer on day 8 after ovulation. Concentrations at $0 \mathrm{~cm}$ are jugular samples. Vertical line indicates site of ultrasound placement of catheter tip when positioned medial to the body of the left kidney.

saphenous vein, using a modification of the method of Benoit and Dailey (1991). A tourniquet was placed above the tarsal joint and the area distal to the joint was shaved and disinfected. Anaesthesia of the region was produced after injection of $10 \mathrm{ml}$ of $2 \%(\mathrm{v} / \mathrm{v})$ lignocaine hydrochloride into the lateral saphenous vein. A 12 gauge $10 \mathrm{~cm}$ needle was then introduced into the lateral saphenous vein following incision of the skin. A polyethylene catheter ( $1 \mathrm{~mm}$ i.d., $2 \mathrm{~mm}$ o.d. medical grade clear vinyl tubing; Dural Plastics, Auburn, NSW) containing a teflon coated wire guide (length $260 \mathrm{~cm}$; Cook Inc., Bloomington, IN) was introduced through the lumen of the needle into the lateral saphenous vein to a mark at $100 \mathrm{~cm}$. After removing the needle, the tourniquet was released and placement of the catheter tip within the caudal vena cava was confirmed using transrectal ultrasonography (7.5 MHz transducer), as described by Norman and Fields (1993). The aorta was palpated rectally and visualized as a pulsating noncompressible large vessel, and the caudal vena cava was located laterally as an easily compressible thin walled vessel, within which the wire guide could be identified as a thin echogenic line. The tip of the guide was positioned medial to the body of the left kidney, as identified by palpation and ultrasonic visualization. This position had previously been validated as corresponding to the site of maximum concentration of progesterone, when blood samples were obtained sequentially at $5 \mathrm{~cm}$ intervals of catheter insertion into the lateral saphenous vein (see Fig. 1). After successful placement of the catheter, the wire guide was removed; the catheter was filled with heparinized saline solution (50 iu ml ${ }^{-1}$ sodium heparin in $0.9 \%(\mathrm{w} / \mathrm{v})$ saline), and the end was sealed and bandaged to the leg.

\section{Sampling procedures}

Heifers were tethered in pairs in adjoining pens, allowed free access to food and water and were able to lie down. Blood samples were withdrawn through remote catheter lines $(2 \mathrm{~mm}$ i.d., $3 \mathrm{~mm}$ o.d.) connected to i.v. catheters, which extended outside the pens to minimize disturbance of the animals. Twice the volume of the sampling catheter was discarded immediately before withdrawal of a $10 \mathrm{ml}$ blood sample and the catheters were flushed with heparin saline solution (12.5 iu sodium 
heparin $\mathrm{ml}^{-1}$ in $0.9 \%(\mathrm{w} / \mathrm{v})$ saline) immediately after each sample was collected.

Blood samples were collected at $15 \mathrm{~min}$ intervals, commencing between $07: 00 \mathrm{~h}$ and 08:00 $\mathrm{h}$, for $24 \mathrm{~h}$ from each animal on each day of blood collection. In addition, jugular blood samples were collected daily from each animal throughout the interovulatory interval. Samples were immediately placed into heparinized tubes and cooled on ice. Plasma was separated by centrifugation at $3000 \mathrm{~g}$ for $15 \mathrm{~min}$ within $2 \mathrm{~h}$ of collection and stored at $-20^{\circ} \mathrm{C}$ for subsequent hormone analysis.

\section{Radioimmunoassays}

Plasma concentrations of LH were measured by doubleantibody radioimmunoassay, using a modification of the method described by Niswender et al. (1969). Purified bovine LH (USDA-bLH-B-6, AFP-11743-B) was provided by D. Bolt (USDA Animal Hormone Program, Beltsville, MD). The antiserum used was NIDDK-anti-oLH-1 (AFP-192279), supplied by NIDDK, Bethesda, MD. Iodination of bLH was performed using a modification of the chloramine- $T$ method described by Bolt and Rollins (1983). All assay reagents were prepared in $0.04 \mathrm{~mol}$ phosphate buffered saline $\mathrm{I}^{-\mathrm{I}}(\mathrm{pH}$ 7.2) containing $50 \mathrm{mg}$ egg albumin $\mathrm{ml}^{-1}$ (RIAD; McNeilly et al., 1976). Duplicate $100 \mu \mathrm{l}$ of standards or samples were incubated with $50 \mu \mathrm{l}$ of normal rabbit serum (diluted 1:250 in RIAD), $50 \mu \mathrm{l}$ of antiserum (1:400 000 dilution in RIAD) and $50 \mu \mathrm{l}$ of tracer (12 000 c.p.m.) for 24 h. Donkey anti-rabbit serum (50 $\mu$ IDS; Boldon, Tyne and Wear), diluted I:25 in RIAD, was then added and the tubes incubated for $18 \mathrm{~h}$ at $4^{\circ} \mathrm{C}$. After addition of $300 \mu \mathrm{l}$ of RIAD, the tubes were centrifuged at $3000 \mathrm{~g}$ for $30 \mathrm{~min}$ at $4^{\circ} \mathrm{C}$. Supernatants were decanted and the radioactivity of the pellet was determined. Increasing volumes $(3.125-100 \mu \mathrm{l})$ of plasma in three pools produced displacement of the radioligand that paralleled the standard curve. Quantitative recovery of added $\mathrm{LH}$ was evaluated by adding $0,0.31$, $0.63,1.25,2.50$ and $5.0 \mathrm{ng}$ USDA-bLH-B-6 to three plasma pools. There was a linear relationship between concentrations of $\mathrm{LH}$ recovered and $\mathrm{LH}$ added. The interassay coefficients of variation (CVs) for two bovine plasma pools of 0.373 and $1.886 \mathrm{ng} \mathrm{ml}^{-1}$ were 10.2 and $6.7 \%$, respectively. The intraassay CVs for the same plasma pools were 9.8 and $5.2 \%$, respectively. Assay sensitivity, defined as concentration at $90 \%$ of maximum binding, was $0.2 \mathrm{ng} \mathrm{ml}^{-1}$.

The concentrations of FSH were determined by doubleantibody radioimmunoassay (Wolfe et al., 1989) using rabbit anti-serum against ovine FSH (JAD-RaOFSH 17-6,7,9) and highly purified ovine FSH (LER-1976-A2) as the labelled hormone and standard. The intra- and interassay CVs were $3.6 \%$ and $17 \%$, respectively. The assay sensitivity was $0.23 \mathrm{ng} \mathrm{ml}^{-1}$. The concentrations of oestradiol in plasma were determined by radioimmunoassay following ether extraction (Kojima et al., 1992). Intra- and interassay CVs were $2.7 \%$ and $15.7 \%$, respectively. The assay sensitivity was $0.08 \mathrm{pg} \mathrm{ml}^{-1}$.

The concentrations of progesterone in plasma were determined in unextracted plasma samples using a modification of the Danazol method (McGinley and Casey, 1979) described by Jolly (1992). Samples were diluted as necessary using charcoalextracted steer plasma. The interassay $\mathrm{CVs}$ for two bovine serum pools of 0.98 and $3.93 \mathrm{ng} \mathrm{ml}^{-1}$ were 14.9 and $13.2 \%$, respectively. The intra-assay CVs for the same serum pools were 13.5 and $11.9 \%$, respectively. The assay sensitivity, as defined by concentration at $90 \%$ of maximum binding, was $0.04 \mathrm{ng} \mathrm{ml}^{-1}$.

\section{Statistical analyses}

The mean concentration, basal concentration, frequency and amplitude of pulses for each of the four hormones during the separate periods of serial blood collection were determined using a modified version of the algorithm developed by Merriam and Wachter (1982), adapted for IBM-compatible personal computers (PULSAR: R. Lazarus, Department of Community Medicine, Westmead Hospital, NSW). The ' $G$ ' parameters used were those derived empirically for $\mathrm{LH}$ profiles by Merriam and Wachter (1982), namely 3.8, 2.6, 1.9, 1.5 and 1.2 for $G(1)$ to $G(5)$, respectively. Precision profiles were derived separately for each hormone.

Variation in the characteristics of hormone release between growth and plateau phases, and between plateau and regression phases were evaluated using paired $t$ tests. The percentage of pulses of oestradiol and progesterone that followed pulses of LH within $60 \mathrm{~min}$ were compared for the three sampling periods using logistic regression analysis. A chi-squared analysis was used to determine whether pulses of oestradiol or progesterone were more likely to occur in the $60 \mathrm{~min}$ following a pulse of $\mathrm{LH}$ compared with sampling times not following a pulse of LH. Relationships between peaks of $\mathrm{LH}$ and concentrations of oestradiol and progesterone were determined using analysis of variance, with the main effects of animal, period, sampling time relative to the $\mathrm{LH}$ peak and all first order interactions included in the model; terms were dropped if non-significant $(P>0.05)$.

\section{Results}

The three sampling periods were, on average ( \pm SEM), $2.5 \pm 0.2, \quad 5.6 \pm 0.3$ and $8.2 \pm 0.4$ days after ovulation, for the growth, plateau and regression phases, respectively. The second dominant ovarian follicle emerged $7.7 \pm 0.5$ days after ovulation. In one heifer, the catheter became blocked following the first period of serial sampling; the results for this animal were therefore excluded from the analyses. The mean diameter of the largest follicle increased from $6.8 \pm 0.5$ to $9.8 \pm 0.2 \mathrm{~mm}$ $(P<0.01)$ and the corpus luteum from $11.2 \pm 1.0$ to $16.0 \pm 1.3 \mathrm{~mm}(P<0.001)$ between growth and plateau phases, respectively; but there was no change in diameter between the plateau and regression phases for the largest follicle $(P=0.26)$ or corpus luteum $(P=0.12)$. Representative profiles of daily changes in the diameter of the corpus luteum and largest follicles from one heifer are shown (Fig. 2).

The frequency of pulses of $\mathrm{LH}$, oestradiol and progesterone tended to change in a coordinated fashion; they were lowest during the plateau phase of the dominant follicle (Table 1). The amplitude of pulses of oestradiol decreased between the growth and plateau phases $(P=0.03)$, but did not change between the plateau and regression phases $(P=0.41)$. The frequency of pulses of $\mathrm{LH}$ decreased between the growth and 


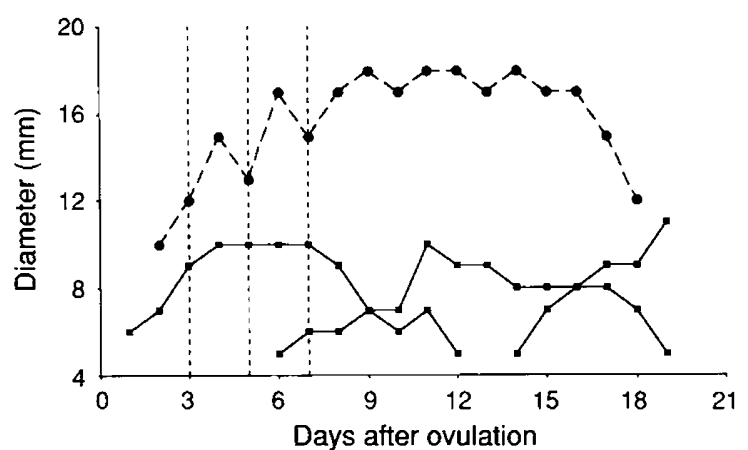

Fig. 2. Diameter of dominant follicles ( $\bullet$ ) and corpus luteum (•) during a complete interovulatory interval for one heifer. Days of collection of serial samples are indicated by vertical lines.

plateau phases $(P=0.06$, Table 1$)$. However, there was little indication of pulsatile release of FSH, with eight of the 15 periods of serial blood collection having no pulses of FSH (data not shown).

Changes in mean concentrations of $\mathrm{LH}$ reflected changes in frequency of pulses of $\mathrm{LH}$; the mean concentration of $\mathrm{LH}$ decreased between the growth and plateau phases $(P=0.04$, Table 2). Similarly, mean concentrations of oestradiol in ovarian venous samples decreased between the growth and plateau phases $(P=0.03$, Table 2). Mean concentrations of progesterone in the caudal vena cava increased between the growth and plateau phases, whereas mean concentrations of FSH were $0.2 \mathrm{ng} \mathrm{ml}^{-1}$ greater between the plateau and regression phases $(P<0.05$, Table 2$)$.

Changes in concentrations of oestradiol and progesterone in the jugular vein were lower but mirrored changes in concentrations of samples collected from the caudal vena cava (Table 2). Concentrations of progesterone in the caudal vena cava were $>2.5$ times higher than jugular concentrations in all experimental heifers and were, on average, 6.8 times greater than those in the jugular vein. However, it was only during the growth phase that concentrations of oestradiol were greater, by a factor of 2.8 , in the caudal vena cava than in the jugular vein.
There was no effect of period of serial blood collection on the percentage of $\mathrm{LH}$ pulses that were followed by either a pulse of oestradiol $(P=0.25)$ or progesterone $(P=0.32)$ within $60 \mathrm{~min}$ of the peak release of LH. Overall, $56 \%$ of $\mathrm{LH}$ pulses were followed by pulses of oestradiol, which was greater than the percentage expected by chance, given the mean observed frequency of oestradiol pulses of $0.37 \mathrm{~h}^{-1}\left(\chi_{(3)}^{2}=7.63\right.$, $P=0.05$ ). Examination of concentrations of oestradiol in all plasma samples obtained following pulses of $\mathrm{LH}$ revealed an increase in mean concentration of oestradiol of $2.81 \pm 0.82 \mathrm{pg}$ $\mathrm{ml}^{-1}$ within $15 \mathrm{~min}$ of the peak release of LH $(P<0.001$, Fig. 3).

The percentage of LH pulses followed by pulses of progesterone was $35 \%$, which was no different to the percentage expected by chance, given the observed frequency of pulses of progesterone of $0.32 \mathrm{~h}^{-1}\left(\chi_{(3)}^{2}=0.02, P=0.99\right)$. In addition, mean concentrations of progesterone did not change following a pulse of $\mathrm{LH}(P=0.19$, Fig. 4). The relationships between $\mathrm{LH}$ pulses and concentrations of oestradiol or progesterone did not differ among days of serial blood collection $(P=0.48$ and 0.61 , respectively).

\section{Discussion}

The frequency of pulses and mean concentrations of $\mathrm{LH}$ were greatest during the growth phase of the first dominant follicle of the oestrous cycle, when secretion of oestradiol was greatest and peripheral concentrations of progesterone were $<1.0 \mathrm{ng} \mathrm{ml}^{-1}$. Concentrations of $\mathrm{LH}$ decreased during the plateau phase in association with a decrease in the frequency of pulses of $\mathrm{LH}$, probably owing to increased peripheral concentrations of progesterone. Price and Webb (1988) found that treatment of ovariectomized heifers with progesterone alone decreased the frequency but did not change the amplitude of pulses of LH. In contrast, treatment with oestradiol alone suppressed release of LH by decreasing the amplitude but not the frequency of LH pulses. Similarly, Stumpf et al. (1993) reported that the frequency of pulses of LH was significantly lower in ovariectomized cows treated with progesterone alone, compared with those treated with oestradiol alone.

Table 1. Characteristics of pulsatile release of hormones in five heifers during three periods of serial blood collection from the caudal vena cava (mean \pm SEM), with significance of difference between periods $(P)$

\begin{tabular}{|c|c|c|c|c|c|}
\hline \multirow[b]{2}{*}{ Parameter } & \multicolumn{3}{|c|}{ Period of collection ${ }^{a}$} & \multicolumn{2}{|c|}{$P$} \\
\hline & 1 & 2 & 3 & Period 1 and 2 & Period 2 and 3 \\
\hline \multicolumn{6}{|l|}{ Pulse frequency $h^{-i}$} \\
\hline LH & $0.41 \pm 0.06$ & $0.23 \pm 0.03$ & $0.28 \pm 0.08$ & 0.06 & 0.52 \\
\hline FSH & $0.03 \pm 0.03$ & $0.06 \pm 0.02$ & $0.03 \pm 0.02$ & 0.34 & 0.43 \\
\hline Oestradiol & $0.50 \pm 0.11$ & $0.23 \pm 0.05$ & $0.38 \pm 0.11$ & 0.16 & 0.30 \\
\hline Progesterone & $0.39 \pm 0.09$ & $0.19 \pm 0.06$ & $0.38 \pm 0.07$ & 0.14 & 0.22 \\
\hline \multicolumn{6}{|l|}{ Pulse amplitude } \\
\hline LH (ng ml ${ }^{-1}$ ) & $0.29 \pm 0.02$ & $0.38 \pm 0.03$ & $0.48 \pm 0.12$ & 0.12 & 0.36 \\
\hline Oestradiol $\left(\mathrm{pg} \mathrm{m}^{-1}\right)$ & $11.97 \pm 2.44$ & $3.41 \pm 0.78$ & $6.14 \pm 2.77$ & 0.03 & 0.41 \\
\hline Progesterone $\left(\mathrm{ng} \mathrm{ml}^{-1}\right)$ & $7.26 \pm 3.14$ & $11.73 \pm 2.18$ & $34.25 \pm 11.43$ & 0.32 & 0.17 \\
\hline
\end{tabular}

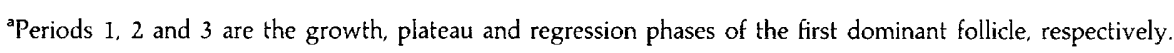


Table 2. Concentrations of hormones in the caudal vena cava (CVC) and jugular vein of five heifers during three periods of serial blood collection (mean $\pm \mathrm{SEM}$ ), with significance of difference between periods $(P)$

\begin{tabular}{|c|c|c|c|c|c|}
\hline \multirow[b]{2}{*}{ Parameter } & \multicolumn{3}{|c|}{ Period of collection ${ }^{a}$} & \multicolumn{2}{|c|}{$P$} \\
\hline & 1 & 2 & 3 & Period 1 and 2 & Period 2 and 3 \\
\hline \multicolumn{6}{|l|}{ Mean concentration (CVC) } \\
\hline $\mathrm{LH}\left(\mathrm{ng} \mathrm{ml}^{-1}\right)$ & $0.43 \pm 0.05$ & $0.36 \pm 0.04$ & $0.34 \pm 0.03$ & 0.04 & 0.25 \\
\hline $\mathrm{FSH}\left(\mathrm{ng} \mathrm{ml}{ }^{-1}\right)$ & $1.77 \pm 0.07$ & $1.86 \pm 0.03$ & $1.66 \pm 0.08$ & 0.29 & 0.04 \\
\hline Oestradiol (pg ml ${ }^{-1}$ ) & $11.49 \pm 2.67$ & $3.07 \pm 0.21$ & $4.35 \pm 1.71$ & 0.03 & 0.46 \\
\hline Oestradiol $\left(\mathrm{pg} \mathrm{ml} \mathrm{ml}^{-1}\right)$ & $5.28 \pm 0.85$ & $2.77 \pm 0.27$ & $2.68 \pm 0.57$ & 0.02 & 0.83 \\
\hline Progesterone (ng ml ${ }^{-1}$ ) & $0.89 \pm 0.22$ & $2.60 \pm 0.23$ & $3.87 \pm 0.66$ & 0.01 & 0.16 \\
\hline
\end{tabular}

${ }^{\mathrm{a}}$ Periods 1,2 and 3 are the growth, plateau and regression phases of the first dominant follicle, respectively.

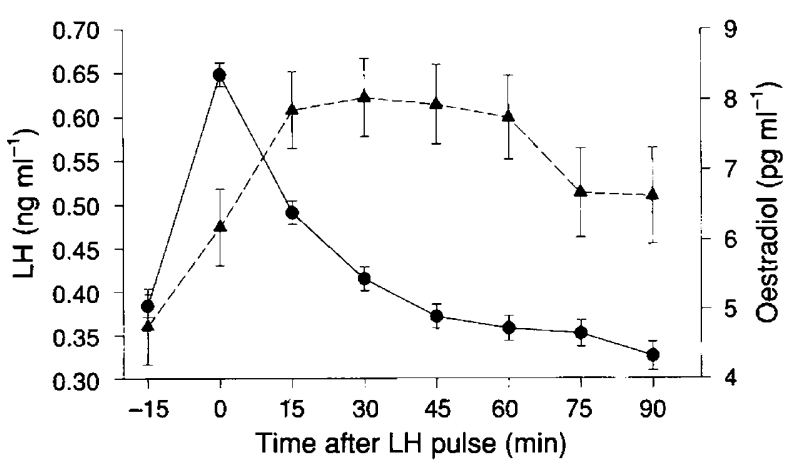

Fig. 3. Concentrations of $\mathrm{LH}\left(\mathrm{ng} \mathrm{ml}^{-1} \bullet\right.$ ) and oestradiol (pg ml $\left.{ }^{-1} \Delta\right)$ in the caudal vena cava of five heifers around the time of detection of all $\mathrm{LH}$ pulses (least squares means \pm SEM).

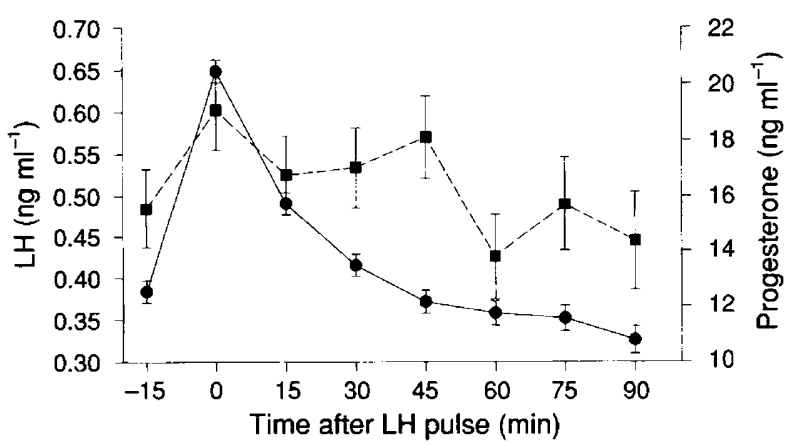

Fig. 4. Concentrations of LH (ng $\mathrm{ml}^{-1} \bullet$ ) and progesterone (ng ml ${ }^{-1}$ a) in the caudal vena cava of five heifers around the time of detection of all LH pulses (least squares means \pm SEM).

The amplitude of pulses and mean concentration of oestradiol were greatest during the growth phase of the first dominant follicle of the oestrous cycle and were significantly reduced when the dominant follicle attained its largest diameter. This increased secretion of oestradiol was associated with a high frequency release of LH pulses, supporting the conclusion of Walters et al. (1984) that oestradiol production is determined by the frequency of $\mathrm{LH}$ pulses. Comparing the plateau and regression phases, there were no differences in the amplitude or frequency of oestradiol pulses, or in the mean concentration of oestradiol in the caudal vena cava. These findings are in agreement with in vitro results from bovine ovarian follicles collected 5,8 or 12 days after behavioural oestrus (Badinga et al., 1992). Concentrations of oestradiol in the follicular fluid of dominant follicles were greater on day 5 compared with day 8 or 12 , which corresponded with a small increase in plasma oestradiol on day 4 . The decrease in production of oestradiol by dominant follicles when they attained maximum diameter may also be due to a decrease in the numbers of receptors for $\mathrm{LH}$ between the growth and plateau phases, as reported by Rollosson et al. (1994). As dominant ovarian follicles increase in size, the ability to bind human chorionic gonadotrophin increases (Ireland and Roche, 1983) and as a single ovarian follicle becomes dominant, increased secretion of oestradiol by this follicle occurs and unequal concentrations of oestradiol in the two utero-ovarian veins is the net result (Ireland et al., 1984). It was not possible to determine from the current study the relative contribution of dominant and subordinate follicles to concentrations of oestradiol in the caudal vena cava; however, it is possible that during the regression phase the emerging group of follicles made some contribution. Sunderland et al. (1994) reported that follicular fluid concentrations of oestradiol were greater in small, newly emerged follicles than in dominant follicles of beef heifers on day 12 of the oestrous cycle.

In agreement with the current findings of a decreased release of oestradiol by the dominant follicle when it had attained its largest diameter, Kaneko et al. (1991) reported that peripheral concentrations of oestradiol in the plasma of cows increased with growth of the dominant ovarian follicle, but decreased 6 days after the preovulatory surge of $\mathrm{LH}$, although the dominant follicle continued to increase in size. Similarly, Guilbault et al. (1993b) found that peak concentrations of oestradiol occurred about 4 days before the cessation of growth of the first dominant follicle of the oestrous cycle. During the period of follicular dominance, growth of secondary follicles is halted, indicating that dominance of the largest follicle, as defined by its ability to suppress the growth of other ovarian follicles, is not solely related to the secretion of oestradiol. 
The association between pulses of $\mathrm{LH}$ and oestradiol in the current study was not as great as that reported by others. On average, $56 \%$ of LH pulses were followed by a pulse of oestradiol within $60 \mathrm{~min}$ of peak release of LH. The temporal relationship between pulses of LH and oestradiol was first detected in ewes during the breeding season by Baird et al. (1976), who found that LH pulses were followed, within $5 \mathrm{~min}$, by an increased release of oestradiol, which reached a peak in $30 \mathrm{~min}$. Walters et al. (1984) reported that $>90 \%$ of gonadotrophin pulses were associated with pulses of oestradiol in cows, with a mean time-lag of approximately $24 \mathrm{~min}$. It may be that the smaller dominant follicle of Bos indicus heifers (Rhodes et al., 1994), compared with Bos taurus cows, secretes less oestradiol in response to stimulation by LH. The nearly sevenfold difference in the concentrations of progesterone in the caudal vena cava compared with jugular concentrations indicates that incorrect catheter placement could not have been the cause of the lower detection rate of gonadal hormone pulses in the current compared with previous studies. Nevertheless, there was a significant increase in the mean concentration of oestradiol following each LH pulse, which reached a maximum between 15 and 30 min after the peak release of $\mathrm{LH}$. In addition, this relationship did not vary with the period of serial blood collection, in agreement with the findings of Walters et al. (1984), who report that pulses of oestradiol were associated with $90 \%$ and $96 \%$ of pulses of $\mathrm{LH}$ during the early and mid-luteal phases of the oestrous cycle, respectively, in spite of a significant decrease in the amplitude of pulses of oestradiol. The temporal relationship between release of LH and oestradiol, therefore, does not appear to be influenced by the stage of oestrous cycle.

The frequency of progesterone pulses did not vary with the period of serial blood collection and there was no apparent relationship between the mean concentrations of progesterone and peak release of $\mathrm{LH}$, in agreement with the findings of Baird et al. (1976) in ewes. Secretion of progesterone by corpora lutea was reported to be episodic in a number of other studies (Walters et al., 1984; Benoit and Dailey, 1991; McNeilly et al., 1992). Moreover in heifers, Peters et al. (1993) reported that stimulation by $\mathrm{LH}$ pulses is required for the normal function of corpora lutea from day 2 to day 12 , but not from day 12 to day 17 of the oestrous cycle. In contrast, Scottish Blackface ewes treated with an antagonist of GnRH on day 4 or day 11 of the oestrous cycle have continued episodic secretion of progesterone in the absence of pulsatile secretion of $\mathrm{LH}$, and do not differ in the timing of luteolysis compared with control animals (McNeilly et al., 1992). Therefore, the cause of pulsatile release of progesterone remains unknown, but may lie within the corpus luteum itself. More than $80 \%$ of the progesterone secreted by the corpus luteum is produced by large luteal cells, which seem to be independent of LH stimulation (Niswender et al., 1994).

There was little evidence of FSH pulses in the current experiment compared with the study of Walters et al. (1984), who reported a high degree of association between pulses of FSH and progesterone. However, pulses of FSH and LH were also closely associated and it has been suggested that there might have been significant crossreactivity between FSH and LH in the assay system used in the previous study (Butler $e$ t al., 1983).
The concentrations of FSH during the plateau phase (mean $=5.6$ days after ovulation) were greater than during the regression phase (mean $=8.2$ days after ovulation). This increase in FSH occurred approximately 2 days before the day of detection of the second dominant follicle, in agreement with the findings of previous authors. Adams et al. (1992) reported high concentrations of circulating FSH 1-2 days before the emergence of a new wave of follicles and concluded that a surge in release of FSH necessarily precedes the emergence of a new wave of ovarian follicular growth in cattle. Similarly, Sunderland et al. (1994) reported transient increases in serum concentrations of FSH before the selection of a dominant follicle. In addition, Turzillo and Fortune (1990) showed that treatment of heifers with bovine follicular fluid from 12 to $60 \mathrm{~h}$ after the onset of behavioural oestrus abolishes the postovulatory rise in $\mathrm{FSH}$ and delays the appearance of the first dominant ovarian follicle. It is hypothesized that, in cattle, increases in circulating concentrations of FSH initiate the development of new phases of dominant follicle growth (Sunderland et al., 1994).

In conclusion, mean concentrations and the amplitude of pulses of oestradiol were found to be high only during the growth phase of the largest ovarian follicle and were significantly reduced when this follicle attained maximum diameter, during the plateau phase. In addition, increased secretion of oestradiol was associated with increased frequency of pulsatile release of LH by the pituitary. Compared with the regression phase, mean concentrations of FSH were increased during the plateau phase of dominant follicle development, which occurred approximately 2 days before the day of emergence of the second dominant follicle. This increase in FSH, in conjunction with the decrease in the release of oestradiol, may be an indication of the loss of functional dominance by the largest ovarian follicle of the first wave of follicular growth, following the decreased release of $\mathrm{LH}$ during the oestrous cycle of bovine females.

This study was partially funded by the Australian Meat Research Corporation. Reagents used in assays were kindly provided by D. Bolt, USDA Animal Hormone Program and the NIDDK ( $\mathrm{LH}$ assay), J. Dias (FSH assay) and N. Mason (oestradiol assay). The statistical advice of G. De'ath, the assistance of S. Stobart, C. Coleman and J. Cave in animal handling and collection of blood samples and D. Clopton with hormone assays is gratefully acknowledged. This paper was published as paper number 11028 , journal series Nebraska Agricultural Research Division.

\section{References}

Adams GP, Matteri RL, Kastelic JP, Ko JCH and Ginther OJ (1992) Association between surges of follicle stimulating hormone and the emergence of follicular waves in heifers Journal of Reproduction and Fertility 94 177-188

Badinga L, Driancourt MA, Savio JD, Wolfenson D, Drost M, de la Sota RL and Thatcher WW (1992) Endocrine and ovarian responses associated with the first-wave dominant follicle in cattle Biology of Reproduction 47 871-883

Baird DT, Swanston I and Scaramuzzi RJ (1976) Pulsatile release of LH and secretion of ovarian steroids in sheep during the luteal phase of the estrus cycle Endocrinology 98 1490-1496

Benoit AM and Dailey RA (1991) Catheterisation of the caudal vena cava via the lateral saphenous vein in the ewe, cow, and gilt: an alternative to utero-ovarian and medial coccygeal vein catheters Journal of Animal Science $692971-2979$ 
Bolt DJ and Rollins R (1983) Development and application of a radioimmunoassay for bovine follicle-stimulating hormone Journal of Animal Science 56 146-154

Butler WR, Katz LS, Arriola J, Milvae RA and Foote RH (1983) On the negative feedback regulation of gonadotrophins in castrate and intact cattle with comparison of two FSH radioimmunoassays Journal of Animal Science 56 919-929

Driancourt MA (1991) Follicular dynamics in sheep and cattle Theriogenology 35 55-79

Findlay JK (1993) An update on the roles of inhibin, activin, and follistatin as local regulators of folliculogenesis Biology of Reproduction 48 15-23

Guilbault LA, Rouillier P, Matton P, Glencross RG, Beard AJ and Knight PJ (1993a) Relationships between the level of atresia and inhibin contents ( $\alpha$ subunit and $\alpha-\beta$ dimer) in morphologically dominant follicles during their growing and regressing phases of development in cattle Biology of Reproduction 48 268-276

Guilbault LA, Bolamba D, Desaulniers DM and Lussier JG (1993b) Follicular and hormonal events associated with the transient increase in estradiol concentrations during the first wave of follicular development in cattle Theriogenology 39228 (Abstract)

Ireland JJ and Roche JF (1983) Development of nonovulatory antral follicles in heifers: changes in steroids in follicular fluid and receptors for gonadotropins Endocrinology 112 150-156

Ireland JJ and Roche JF (1987) Hypotheses regarding development of dominant follicles during a bovine estrous cycle. In Follicular Growth and Ovulation Rate in Farm Animals pp 1-18 Eds JF Roche and D O'Callaghan. Martinus Nijhoff Publishers, Dordrecht

Ireland JJ, Fogwell RL, Oxender WD, Ames K and Cowley JL (1984) Production of estradiol by each ovary during the estrous cycle of cows journal of Animal Science 59 764-771

Jolly PD (1992) Physiological and Nutritional Aspects of Postpartum Acyclicity in Bos indicus Cows PhD thesis, James Cook University of North Queensland

Kaneko H, Terada T, Taya K, Watanabe G, Sasamoto S, Hasegawa $Y$ and Igarashi M (1991) Ovarian follicular dynamics and concentrations of oestradiol-17B, progesterone, luteinizing hormone and follicle-stimulating hormone during the periovulatory phase of the oestrous cycle in the cow Reproduction, Fertility and Development 3 529-535

Kojima N, Stumpf TT, Cupp AS, Werth LA, Roberson MS, Wolfe MW, Kittok RJ and Kinder JE (1992) Exogenous progesterone and progestins as used in estrous synchrony regimens do not mimic the corpus luteum in regulation of luteinizing hormone and 17 $\beta$-estradiol in circulation of cows Biology of Reproduction 47 1009-1017

McGinley R and Casey JH (1979) Analysis of progesterone in unextracted serum: a method using danazol [17 $\alpha$-pregn-4-en-20-yno(2,3-d) isoxazol-17oll, a blocker of steroid binding to proteins Steroids 33 127-138

McNeilly AS, Crow WJ and Fraser HM (1992) Suppression of pulsatile luteinizing hormone secretion by gonadotrophin-releasing hormone antagonist does not affect episodic progesterone secretion or corpus luteum function in ewes Journal of Reproduction and Fertility 96 865-874

McNeilly JR, McNeilly AS, Walton JS and Cunningham FJ (1976) Development and application of a heterologous radioimmunoassay for ovine folliclestimulating hormone Journal of Endocrinology 70 69-79
Merriam GR and Wachter KW (1982) Algorithms for the study of episodic hormone secretion American Journal of Physiology 243 310-318

Niswender GD, Reichert LE Jr, Midgley AR Jr and Nalbanov AV (1969) Radioimmunoassay for bovine and ovine luteinising hormone Endocrinology 84 1166-1173

Niswender GD, Juengel JL, McGuire WJ, Belfiore CJ and Wiltbank MC (1994) Luteal function: the estrous cycle and early pregnancy Biology of Reproduction 50 239-247

Norman ST and Fields MJ (1993) Ultrasound guided cannulation of the caudal vena cava in the bovine for selective sampling of ovarian effluent Theriogenology $39691-701$

Peters KE, Bergfeld EG, Cupp AS, Kojima FN, Mariscal V, Sanchez T, Wehrman ME, Grotjan HE, Hamernik D and Kinder JE (1993) Pulsatile secretion of LH is necessary for development of fully functional corpora lutea (CL) but is not required to maintain CL function in heifers Journal of Animal Science (Supplement 1) 71216 (Abstract)

Price CA and Webb R (1988) Steroid control of gonadotrophin secretion and ovarian function in heifers Endocrinology 122 2222-2231

Rahe CH, Owens RE, Fleeger JL, Newton HJ and Harms PG (1980) Pattern of plasma luteinizing hormone in the cyclic cow: dependence upon the period of the cycle Endocrinology 107 498-503

Rhodes FM, Fitzpatrick LA, De'ath G and Entwistle KW (1994) The effects of follicle wave numbers per oestrous cycle on the ovulatory follicle in Bos indicus heifers Theriogenology $\mathbf{4 1} 284$ (Abstract)

Rollosson MM, Crim JW, Silcox RW and Kiser TE (1994) Density of $\left[{ }^{125} \mathrm{I}\right] \mathrm{hCG}$ binding to the dominant follicle of the first wave of the estrous cycle in cows Journal of Animal Science (Supplement 1) 72231 (Abstract)

Savio JD, Keenan L, Boland MP and Roche JF (1988) Pattern of growth of dominant follicles during the oestrous cycles of heifers Journal of Reproduction and Fertility 83 663-671

Stumpf TT, Roberson MS, Wolfe MW, Hamernik DL, Kittok RJ and Kinder JE (1993) Progesterone, 17 $\beta$-estradiol, and opioid neuropeptides modulate pattern of luteinizing hormone in circulation of the cow Biology of Reproduction 49 1096-1101

Sunderland SJ, Crowe MA, Boland MP, Roche JF and Ireland JJ (1994) Selection, dominance and atresia of follicles during the oestrous cycle of heifers Journal of Reproduction and Fertility 101 547-555

Turzillo AM and Fortune JE (1990) Suppression of the secondary FSH surge with bovine follicular fluid is associated with delayed ovarian follicular development in heifers Journal of Reproduction and Fertility $\mathbf{8 9}$ 643-653

Walters DL, Schams D and Schallenberger E (1984) Pulsatile secretion of gonadotrophins, ovarian steroids and ovarian oxytocin during the luteal phase of the oestrous cycle in the cow Journal of Reproduction and Fertility 71 479-491

Wolfe MW, Stumpf TT, Roberson MS, Wolfe PL, Kittok RJ and Kinder JE (1989) Estradiol influences on pattern of gonadotropin secretion in bovine males during the period of changed responses to estradiol feedback in age-matched females Biology of Reproduction 41 626-634 